\title{
Zolpidem-Induced Narcolepsy, Faint, Seizure or Coma? A Case Report
}

\author{
Abdolhamid Parsa, Amir Mohammadkhan, Mohammad Babaeian* \\ School of Pharmacy, Shahid Beheshti University of Medical Sciences, Tehran, Iran \\ Email: ^babaeianm@gmail.com
}

How to cite this paper: Parsa, A., Mohammadkhan, A. and Babaeian, M. (2017) Zolpidem-Induced Narcolepsy, Faint, Seizure or Coma? A Case Report. Case Reports in Clinical Medicine, 6, 31-35. https://doi.org/10.4236/crcm.2017.62004

Received: December 20, 2016

Accepted: February 14, 2017

Published: February 17, 2017

Copyright (c) 2017 by authors and Scientific Research Publishing Inc. This work is licensed under the Creative Commons Attribution International License (CC BY 4.0).

http://creativecommons.org/licenses/by/4.0/ (c) (i) Open Access

\begin{abstract}
Zolpidem, as an imidazopyridine agent, is a widely prescribed drug among practitioners for short-term treatment of insomnia. Nevertheless, there have been a number of cases associated with the adverse effects of the stated drug recently. Many cases of serious complications induced by high dose of zolpidem have been reported. Further to the existing reports of adverse reactions to zolpidem, throughout the current manuscript, another case of zolpidem-induced loss of consciousness is going to be presented. The case had taken $100 \mathrm{mg}$ of zolpidem and afterwards, went into an unknown status of narcolepsy, faint, seizure or transient coma. Overdosing zolpidem and being affected by its central effects, he performed risky actions such as cooking by a gas oven and eating meal while intoxicated. The current case suggests that zolpidem overdose might contribute to loss of consciousness and exhibition of high-risk behaviors.
\end{abstract}

\section{Keywords}

Zolpidem, Eating Behavior, Faint, Narcolepsy, Seizure, Coma

\section{Introduction}

Zolpidem (ZLP) as an imidazopyridine is commonly used for short-term treatment of insomnia [1]. It seems to have milder side effects compared with the other hypnotics like benzodiazepines [2]. Side effects associated with ZLP have been commonly reported. The most frequently reported side effects of ZLP in the medical literature are as follows: dizziness, malaise, agitation, headache, hallucination, nightmares, and nausea [3].

Although ZLP appears to be well-tolerated in adults and the elderly [4], there is a host of reports of its abuse, dependence and withdrawal syndrome. It is worth mentioning that in the majority of these reported cases, the recommended dose of ZLP is exceeded and most of the patients have a history of substance 
abuse and/or psychiatric disorder [5] [6].

Further to the growing reports of zolpidem's adverse drug reactions, hereby a case in which zolpidem overdose's consequences have been observed will be presented.

\section{Case Presentation}

A 27-year-old unmarried male pharmacist who was living alone in a microapartment in Tehran, Iran without any known mood disorder or neuropsychological disease (according to his declaration) met a psychiatrist to share his problem and to get advice.

The stated case had been using ZLP irregularly but frequently during the past 4 years. He did not have any history of using other drugs. During the recent 2 years, he had been using ZLP more frequently and in higher doses $(10-80 \mathrm{mg})$. He had been completely forgetting the events of the nights when he took ZLP. He used to use ZLP for his insomnia, but in the aftermath of frequent use, he became interested in the pleasurable mental experiences of this drug, especially eating-related behavior. He believed that when he took ZLP, eating and drinking became more favorable than usual. In this due, he had tended to have dinner after taking ZLP.

As the case declared later about the events, he was suffering a dramatically gloomy night on November 30th 2016. He took 10 tablets of ZLP $10 \mathrm{mg}$ with a full glass of water at 10:30 P.M. He heated up the meal on a gas oven and started to eat. He could not recall the rest of the story. He woke up at 3:30 A.M. and found himself on the floor among the leftovers of the night before. He also noticed that some food had remained in his buccal space. He rinsed out his mouth and since he was feeling well, he did not see the necessity of receiving any clinical care.

\section{Discussion}

Tolerance, dependence and adverse effects associated with the abuse of benzodiazepines and Z-drugs have become a serious public health issue [7] [8] [9]. ZLP as a very commonly prescribed Z-drug has the potential for both medical misuse-when it is taken for long term without or against medical advice-and recreational use - when it is abused to achieve a "high" [8] [9] [10] [11].

There have been reports of some ZLP overdose catastrophic consequences, such as suicide attempt, seizure and coma. Mortaz Hejri et al. have reported a young male case that had used $20 \mathrm{mg}$ of ZLP and as a result of a change in thoughts; he attempted suicide by using more $60 \mathrm{mg}$ of ZLP [12]. A case with recurrent syncopes under long-term intake of ZLP $(10 \mathrm{mg} /$ day) was reported in 2016. The authors of the report suggested that ZLP can trigger seizures in human [13]. Kuzniar T. J. et al. have reported a young female case with depression that had developed deep coma with respiratory failure and loss of brainstem reflexes as a result of ZLP overdose. The authors have appended that acute ZLP overdose should be considered in the differential diagnosis of coma with absent 
brainstem reflexes [14]. In 1996, there was a report of a 68-year-old female who had ingested at least $300 \mathrm{mg}$ of ZLP $\left(\right.$ Ambien $\left.^{\odot}\right)$ and had been found dead at her home [15].

In recent years, there have been reported cases of acute delirium and psychosis after ZLP use. There have also been some other reports in which the cases experienced significant changes in their mental status and as a result expressed dangerous behavior. Shuaib et al. have presented a case of a 53-year-old healthcare professional with an acute altered mental status after a trip to Africa. His history revealed an overdose of self-medicated ZLP for insomnia. The authors considered ZLP overdose as a medical and ethical dilemma [16]. Paradis CM et al. have described 2 cases that killed their spouses. Neither of individuals had a history of aggressive behavior. Both had concomitantly taken $10 \mathrm{mg}$ or more of ZLP plus paroxetine [11]. Dang et al. have reported an interesting rare case of a ZLP-induced new onset nocturnal sleep-related eating disorder, where a 45year-old male ZLP user performed an unexpected and bizarre eating behavior during somnambulistic state [17].

ZLP-induced acute altered mental status is possible even in recommended and minimal doses. A case without any history of psychiatric disorder or substance abuse who developed agitation, confusion and hallucination after taking 1 tablet of ZLP $5 \mathrm{mg}$ was reported in 2016 [18].

There is no doubt that our case had been asleep and woke up after some hours, but what had happened before waking up is not certain. He might have fallen asleep during having meal, or might have fainted. He might have gone into convulsion or even have sunk into a transient coma.

\section{Conclusions}

By and large, the following points are worth mentioning:

- As underlined by FDA [19], it is highly advised to use ZLP at the lowest effective dose for the shortest period of time.

- Since the case has not had any history of high-risk behavior, ZLP can be considered as the main reason for the change in the levels of consciousness. Medical examinations such as head computed tomography, electroencephalography and blood test have been necessary for differential diagnosis.

- As observed in this case and based on the clinical evidences [20], ZLP has a very rapid onset of action. It is highly suggested to administer and use ZLP just before bedtime.

- As mentioned in the case of presentation section, the case lost his consciousness while eating and in the morning after he found a remarkable amount of meal in his buccal space. Based on a lot of evidences, ZLP may cause acute changes in eating behavior [21]. Due to probable changes in the level of consciousness, it is highly essential to advise patients not to take ZLP before meal as blockage in the airway is very possible.

- The case attempted to heat up his meal using a gas oven after taking ZLP. Because of the altered level of consciousness, any incident of fire was possible. 
- The case found himself on the floor. He must have fallen due to ZLP central effects. Any kind of trauma, especially head trauma was possible to occur.

- The case should be strictly monitored and receive diagnosis in terms of depression or any other psychiatric illness and, if necessary, appropriate medication should be prescribed for him.

- Since this case is based on personal declarations, further studies are suggested to disclose the true outcomes of zolpidem overdose's consequences.

\section{Acknowledgements}

We would like to acknowledge Mr. Majid Ghobadi, Dr. Sameh Mortaz Hejri, Dr. Houman Alimoradi and Dr. Fatemeh Amraei for their tremendous help and valuable suggestions.

\section{Consent}

A written informed consent was obtained from the patient for the publication of this report.

\section{Conflict of Interest}

All authors certify that they have no affiliations with or involvement in any organization or entity with any financial interest (such as honoraria; educational grants; participation in speakers' bureaus; membership, employment, consultancies, stock ownership, or other equity interest; and expert testimony or patentlicensing arrangements), or non-financial interest (such as personal or professional relationships, affiliations, knowledge or beliefs) in the subject matter or materials discussed in this manuscript.

\section{References}

[1] Langtry, H. and Benfield, P. (1990) Zolpidem. Drugs, 40, 291-313. https://doi.org/10.2165/00003495-199040020-00008

[2] Ganzoni, E., et al. (1995) Zolpidem in Insomnia: A 3-Year Post-Marketing Surveillance Study in Switzerland. Journal of International Medical Research, 23, 61. https://doi.org/10.1177/030006059502300108

[3] Hajak, G. and Bandelow, B. (1998) Safety and Tolerance of Zolpidem in the Treatment of Disturbed Sleep: A Post-Marketing Surveillance of 16,944 Cases. International Clinical Psychopharmacology, 13, 157-167. https://doi.org/10.1097/00004850-199807000-00002

[4] Darcourt, G., et al. (1999) The Safety and Tolerability of Zolpidem-An Update. Journal of Psychopharmacology, 13, 81-93. https://doi.org/10.1177/026988119901300109

[5] Harrison, T. and Keating, G. (2005) Zolpidem. CNS Drugs, 19, 65-89. https://doi.org/10.2165/00023210-200519010-00008

[6] Inagaki, T., Miyaoka, T., Tsuji, S., Inami, Y., Nishida, A. and Horiguchi, J. (2010) Adverse Reactions to Zolpidem: Case Reports and a Review of the Literature. Primary Care Companion to the Journal of Clinical Psychiatry, 12, e1-e8. https://doi.org/10.4088/pcc.09r00849bro

[7] Cardinali, D.P., Golombek, D.A., Rosenstein, R.E., Brusco, L.I. and Vigo, D.E. 
(2016) Assessing the Efficacy of Melatonin to Curtail Benzodiazepine/Z Drug Abuse. Pharmacological Research, 109, 12-23.

https://doi.org/10.1016/j.phrs.2015.08.016S

[8] Keuroghlian, A.S., Barry, A.S. and Weiss, R.D. (2012) Circadian Dysregulation, Zolpidem Dependence, and Withdrawal Seizure in a Resident Physician Performing Shift Work. The American Journal on Addictions/ American Academy of Psychiatrists in Alcoholism and Addictions, 21, 576-577.

https://doi.org/10.1111/j.1521-0391.2012.00273.x

[9] Hajak, G., Müller, W.E., Wittchen, H.U., Pittrow, D. and Kirch, W. (2003) Abuse and Dependence Potential for the Non-Benzodiazepine Hypnotics Zolpidem and Zopiclone: A Review of Case Reports and Epidemiological Data. Addiction, 98, 1371-1378.

https://doi.org/10.1046/j.1360-0443.2003.00491.x

[10] Griffiths, R.R. and Johnson, M.W. (2005) Relative Abuse Liability of Hypnotic Drugs: A Conceptual Framework and Algorithm for Differentiating Among Compounds. Journal of Clinical Psychiatry, 66, 31-41.

[11] Paradis, C.M., Siegel, L.A. and Kleinman, S.B. (2012) Two Cases of Zolpidem-Associated Homicide. Primary Care Companion to CNS Disorder, 14.

[12] Mortaz Hejri, S., Faizi, M. and Babaeian, M. (2013) Zolpidem-Induced Suicide Attempt: A Case Report. DARU Journal of Pharmaceutical Sciences, 21, 77. https://doi.org/10.1186/2008-2231-21-77

[13] Finsterer, J. and Frank, M. (2016) Zolpidem-Triggered Seizures, Depression, and Reduced Locomotion. Journal of Clinical Neuroscience, 33, 271-272. https://doi.org/10.1016/j.jocn.2016.05.034

[14] Kuzniar, T.J., Balagani, R., Radigan, K.A., Factor, P. and Mutlu, G.M. (2010) Coma with Absent Brainstem Reflexes Resulting from Zolpidem Overdose. American Journal of Therapeutics, 17, e172-e174. https://doi.org/10.1097/mjt.0b013e318188bdca

[15] Winek, C.L., Wahba, W.W., Janssen, J.K., Rozin, L. and Rafizadeh, V. (1996) Acute Overdose of Zolpidem. Forensic Science International, 78, 165-168. https://doi.org/10.1016/0379-0738(95)01875-1

[16] Shuaib, W., Beatrice, C. and Abazid, A.G. (2015) Zolpidem Overdose: A Medical and Ethical Dilemma. American Journal of Therapeutics, 23, e1956-e1957. https://doi.org/10.1097/MJT.0000000000000380

[17] Dang, A., Garg, G. and Rataboli, P.V. (2009) Zolpidem Induced Nocturnal SleepRelated Eating Disorder (NSRED) in a Male Patient. International Journal of Eating Disorders, 42, 385-386. https://doi.org/10.1002/eat.20620

[18] Tahir, H., Saleemi, M., Wolfe, C. and Daruwalla, V. (2016) Acute Delirium Caused by Single Small Dose of Zolpidem. American Journal of Medical Case Reports, 4, 137-139.

[19] US Food and Drug Administration (2014) FDA Drug Safety Communication: Risk of Next-Morning Impairment after Use of Insomnia Drugs. FDA Requires Lower Recommended Doses for Certain Drugs Containing Zolpidem (Ambien, Ambien CR, Edluar, and Zolpimist).

[20] Yaripour, S., Rashid, S., Alibakhshi, H. and Mohammadi, A. (2015) Development and Validation of a Stability-Indicating Reversed Phase HPLC Method for the Quality Control of Zolpidem in Bulk and Tablet Dosage Forms. Journal of Analytical Chemistry, 70, 738-743. https://doi.org/10.1134/S1061934815060143

[21] Najjar, M. (2007) Zolpidem and Amnestic Sleep Related Eating Disorder. Journal of Clinical Sleep Medicine, 3, 637-638. 
Submit or recommend next manuscript to SCIRP and we will provide best service for you:

Accepting pre-submission inquiries through Email, Facebook, LinkedIn, Twitter, etc. A wide selection of journals (inclusive of 9 subjects, more than 200 journals)

Providing 24-hour high-quality service

User-friendly online submission system

Fair and swift peer-review system

Efficient typesetting and proofreading procedure

Display of the result of downloads and visits, as well as the number of cited articles Maximum dissemination of your research work

Submit your manuscript at: http://papersubmission.scirp.org/

Or contact crcm@scirp.org 